International Journal of Advanced Chemistry, $8(1)(2020) 15-21$
International Journal of Advanced Chemistry
SPC
Website: www.sciencepubco.com/index.php/IJAC
Research paper

\title{
Determination of fluorescence lifetimes of fluorescein from fluorescence quenching data
}

\author{
Abimbola Ogunsipe ${ }^{1 *}$, Sunday Opeolu ${ }^{2}$ \\ ${ }^{1}$ Department of Chemistry, Federal University of Petroleum Resources, Effurun, P.M.B. 1221, Effurun, Nigeria \\ ${ }^{2}$ Department of Chemical Sciences, Yaba College of Technology, Yaba, P.M.B. 2011, Yaba-Lagos, Nigeria \\ *Corresponding author E-mail: ogunsipe.abimbola@fupre.edu.ng
}

\begin{abstract}
The fluorescence quenching of fluorescein by 1,4-benzoquinone (BQ) in five solvents - methanol, ethanol, phosphate buffer saline (PBS, $\mathrm{pH}$ 7.4), $N, N^{\prime}$-dimethylformamide (DMF) and dimethylsulphoxide (DMSO) is hereby investigated. Fluorescein's fluorescence was effectively quenched by BQ, and the quenching was dynamic (purely collisional) within the BQ's concentration range (0.001 to $0.004 \mathrm{M})$ used in this work. Accordingly, the quenching data were in conformity with the Stern-Volmer's model. Stern-Volmer's constant (Ksv) values range between 17.4 in DMSO and 43.4 in methanol. $\mathrm{K}_{\mathrm{Sv}}$ values, together with the calculated bimolecular rate constants $\left(\mathrm{k}_{\mathrm{D}}\right)$ in the respective solvents, were used to semi-empirically estimate the fluorescence lifetimes $\left(\tau_{\mathrm{F}}\right)$ of fluorescein in the individual solvents. Just as for $\mathrm{K}_{\mathrm{Sv}}$ values, $\tau_{\mathrm{F}}$ values are solvent-viscosity dependent, with the lowest values being obtained in methanol and the highest in DMSO, which are the least and most viscous solvents respectively. $\tau_{\mathrm{F}}$ values obtained in this work are $3.55,3.71,3.78,4.13$ and $4.51 \mathrm{~ns}$ (in methanol, PBS 7.4, ethanol, DMF and DMSO, respectively).
\end{abstract}

Keywords: Fluorescein; Benzoquinone; Fluorescence; Quenching; Lifetime.

\section{Introduction}

Fluorescein, a yellowish-green emitting dye, possesses many attractive photophysicochemical properties (e.g., high molar absorptivity, high fluorescence quantum yield, and high photostability); in addition, it is water-soluble, biocompatible (Ha et al. 2009, Veres et al. 2017) and cheap. These attributes bestow on it considerable versatility, and make it a compound of choice for many industrial applications and in academia. Fluorescein has found application in the production of advanced molecular probes for biological, toxicological, biomedical, and environmental studies (Burchak et al. 2006, Oliveira et al. 2018, Xiong et al. 2014, Zhwng et al. 2013). Fluorescein has been used as a lasing medium (green, 530-560 nm) in laser dyes (Al-Aqmar et al. 2015, Govindanunny \& Sivaram 1980). It is desirable for a dye laser gain medium to possess an appreciably long fluorescence lifetime, and as such, a thorough knowledge of its photophysical properties is worthwhile. Fluorescence lifetime refers to the average time a fluorophore molecule stays in the excited state before emitting a photon and returning to the ground state. Fluorescence lifetime is also an essential consideration for other practical applications of fluorescence such as Fluorescence Resonance Energy Transfer (FRET) and fluorescence lifetime assays, sensing, imaging and imaging microscopy [He et al. 2003, Al et al. 2003, Jose et al. 2007, Becker 2012, Ma et al. 2004); this has necessitated the development of techniques for the estimation of fluorescence lifetime. Fluorescence lifetime is an intrinsic property of a fluorophore, and can be measured in either the frequency domain or the time domain. While both approaches have different instrumentation and data acquisition procedures, they are mathematically equivalent and their data can be interconverted through Fourier transform. The most familiar technique for fluorescence lifetime measurement is time-correlated single photon counting (TCSPC), which simplifies data collection and enhanced quantitative photon counting. A relatively unfamiliar but cheaper and simpler method of fluorescence lifetime determination is hereby presented; this method is based on the diffusion-controlled collisional interaction between the fluorophore and quencher molecules, and data treatment via the Stern-Volmer model (Lakowicz 1999). In this work, 1, 4-benzoquinone is used as a quencher for the quenching of fluorescein's fluorescence; the data treatment ultimately leads to the estimation of the fluorescence lifetimes of fluorescein (Fig. 1) in different solvents. 


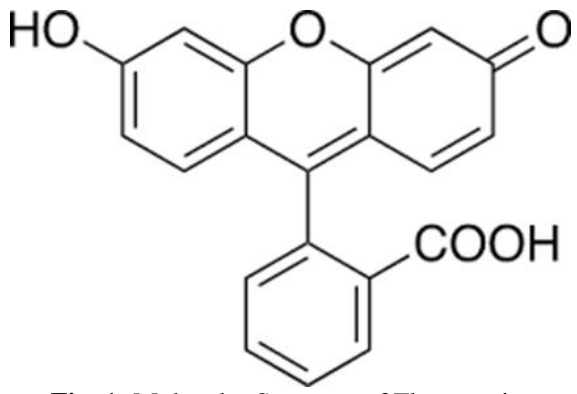

Fig. 1: Molecular Structure of Fluorescein.

\section{Experimental}

\subsection{Materials and equipment}

Fluorescein was purchased from Sigma-Aldrich. N,N'-dimethylformamide (DMF), dimethylsulphoxide (DMSO), methanol, ethanol and ether (diethylether) were obtained from SAARCHEM; water was freshly distilled. Chlorophyll a and benzoquinone (BQ) were purchased from Aldrich.

UV-Vis absorption spectra were recorded on a Varian $500 \mathrm{UV} / \mathrm{visible/NIR}$ spectrophotometer, and fluorescence spectra on a Varian Eclipse spectrofluoremeter.

\subsection{Fluorescence quantum yields}

Fluorescence quantum yields $\left(\Phi_{\mathrm{F}}\right)$, were determined using the comparative method, as described before (Fery-Forgues and Lavabre 1999, Maree et al. 2002, Ogunsipe \& Nyokong 2005a), Eq. 1, using chlorophyll a in ether $\left(\Phi_{\mathrm{F}}=0.32\right.$ (Montalban 1999), as the reference.

$$
\Phi_{\mathrm{F}}=\Phi_{\mathrm{F}}(\mathrm{Std}) \frac{\mathrm{F}_{\mathrm{x}} \cdot \mathrm{Asst}_{\mathrm{std}} \mathrm{n}_{\mathrm{x}}^{2}}{\mathrm{~F}_{\mathrm{std}} \cdot \mathrm{A} \cdot \mathrm{n}_{\mathrm{Std}}^{2}}
$$

$F_{x}$ and $F_{s t d}$ are the areas under the emission curves of the sample and standard, respectively. $A_{x}$ and $A_{s t d}$ are the absorbances of the sample and standard, respectively, and $n_{x}$ and $n_{S t d}$ are the refractive indices of the solvents used for sample and standard, respectively. Both the sample and reference were excited at the same wavelength. The absorbance of the solutions at the excitation wavelength ranged between 0.04 and 0.05 .

\subsection{Fluorescence quenching by benzoquinone}

Fluorescence quenching experiments on fluorescein in methanol, PBS 7.4, ethanol, DMF and DMSO were carried out by the addition of varying (increasing) concentrations of BQ to fluorescein (fixed concentration), and the concentrations of BQ in the resulting mixtures were $0,0.001,0.002,0.003$ and $0.004 \mathrm{M}$. The fluorescence spectra of fluorescein at each BQ concentration were recorded, and the changes in fluorescence intensity at various BQ concentrations were related by the Stern-Volmer (S-V) equation (Eq. 2):

$\frac{\mathrm{I}_{0}}{\mathrm{I}}=1+\mathrm{K}_{s v}[\mathrm{BQ}]$

Where $\mathrm{I}_{0}$ and $\mathrm{I}$ are the fluorescence intensities of fluorescein in the absence and presence of BQ respectively; [BQ], the concentration of the $\mathrm{BQ}$, and $\mathrm{K}_{\mathrm{Sv}}$, the Stern-Volmer constant; which is the product of the bimoleculear quenching constant $\left(\mathrm{k}_{\mathrm{Q}}\right)$ and the fluorescence lifetime $\tau_{\mathrm{F}}$ (Eq. 3):

$\mathrm{KSV}=\mathrm{kQ} \cdot \tau_{\mathrm{F}}$

The ratios $\frac{\mathrm{I}_{0}}{\mathrm{I}}$ were calculated and plotted against $[\mathrm{BQ}]$ according to Eq. 2, and Ksv determined from the slope.

The bimolecular rate constant for diffusion-controlled reactions $\left(\mathrm{k}_{\mathrm{D}}\right)$ is related to the apparent bimolecular quenching constant $\left(\mathrm{k}_{\mathrm{Q}}\right)$ by Eq. 4 (Maree et al. 2002):

$\mathrm{k}_{\mathrm{Q}}=\mathrm{f} \cdot \mathrm{k}_{\mathrm{D}}$

Where $\mathrm{f}$ is the quenching efficiency.

The bimolecular rate constant (kD) can be obtained from the Einsten-Smoluchowski relationship (Eq. 5):

$\mathrm{k}_{\mathrm{D}}=\frac{4 \pi \mathrm{N}_{\mathrm{A}}\left(\mathrm{D}_{\mathrm{Fllc}}+\mathrm{D}_{\mathrm{BQ}}\right)\left(\mathrm{r}_{\mathrm{HRc}}+\mathrm{r}_{\mathrm{BQ}}\right)}{1000}$

Where $\mathrm{N}_{\mathrm{A}}$ is the Avogadro's number; $\mathrm{D}_{\text {Flrc }}$ and $\mathrm{D}_{\mathrm{BQ}}$, the diffusion coefficients of the fluorophore and quencher respectively, while $\mathrm{r}_{\mathrm{FIr}}$ and $\mathrm{r}_{\mathrm{BQ}}$ are the molecular radii of fluorescein and $\mathrm{BQ}$ respectively.

The diffusion coefficient $\mathrm{D}$ is given by the Stokes' equation (Eq. 6). 


$$
\mathrm{D}=\frac{\mathrm{kT}}{6 \pi \eta \mathrm{r}}
$$

Where $\mathrm{k}$ is the Boltzmann constant; $\mathrm{T}$, the absolute temperature; $\eta$, the solvent's viscosity and $\mathrm{r}$, the fluorescein or BQ radius. RFlrc and rBQ is assumed to be equal to the respective molecule's Onsager cavity radius (a), which is obtained from molecular volume, as given by Suppan's equation:

$a=\sqrt[3]{\frac{3 M}{4 \pi \rho N}}$

$\mathrm{M}$ is the molecular weight of fluorescein $\left(332.31 \mathrm{~g} \mathrm{~mol}^{-1}\right)$ or BQ $\left(108.10 \mathrm{~g} \mathrm{~mol}^{-1}\right)$; $\rho$, the density $\left(1.602 \mathrm{~g} \mathrm{~cm}^{-3}\right.$ for fluorescein and $1.32 \mathrm{~g}$ $\left.\mathrm{cm}^{-3} \mathrm{BQ}\right)$; and $\mathrm{N}$, the Avogadro's number.

$\mathrm{k}_{\mathrm{Q}}$ values may be determined from Eq. 4 using the calculated $\mathrm{k}_{\mathrm{D}}$ value, provided that $\mathrm{f}$ is known. From the values of $\mathrm{k}_{\mathrm{Q}}$, the values of $\tau_{\mathrm{F}}$ can then be calculated using Eq. 3.

\section{Results and discussion}

\subsection{Fluorescein structure}

Fluorescein contains the hydroxy and the carboxy groups (Fig. 1), which are active sites that can link electron donors and acceptors to form multicomponent compounds (Zhang et al 1997), hence the multi-functionability of the molecule. The linking of aromatic ring with oxygen makes fluorescein rather rigid, and this has desirable effects on its photophysical properties. For example, fluorescein is known as one of the most fluorescent organic fluorophores.

\subsection{UV-Visible and fluorescence spectra}

The ground state electronic absorption spectra of fluorescein in methanol, water and DMSO is shown in Fig. 2. The absorption bands arise from $\pi-\pi^{*}$ transitions and can be explained in terms of linear combination of HOMO-LUMO transitions. There are multiple absorption bands in the spectra, which imply the occurrence of numerous non-degenerate electronic transitions upon UV-Visible irradiation.

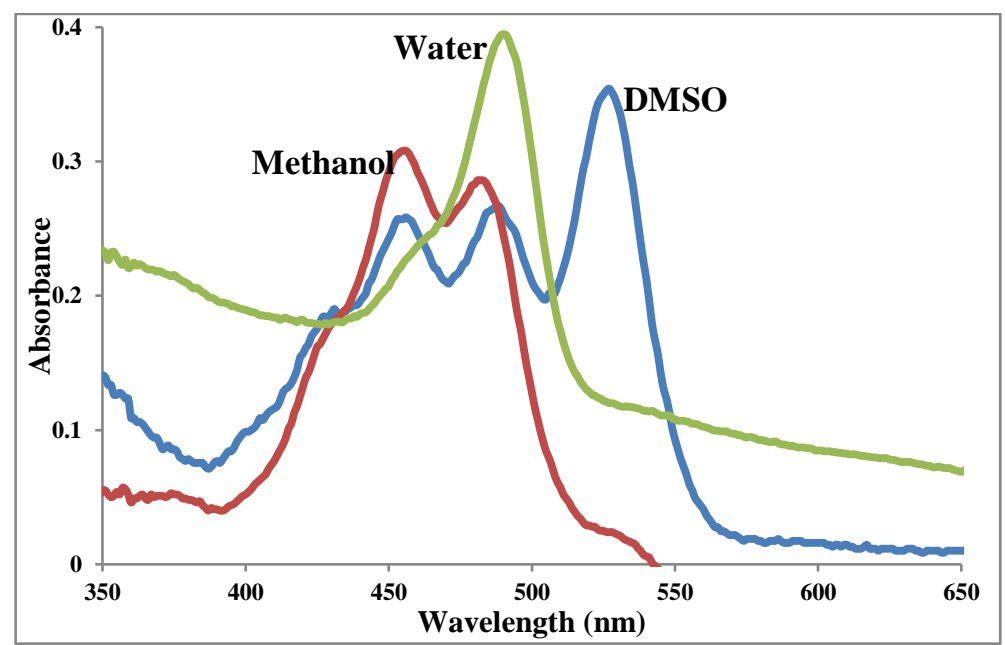

Fig. 2: Absorption Spectra of Fluorescein in Methanol, Water and DMSO.

The UV-vis spectrum of fluorescein has intense bands in the $450-550 \mathrm{~nm}$ spectral expanses, with extinction coefficients greater than $10^{4} \mathrm{~L} \mathrm{~mol}^{-1} \mathrm{~cm}^{-1}$, accompanied by a series of vibrational bands. Fig. 3 (and Table 1) shows the absorption and emission spectra (normalized and overlaid) of fluorescein in DMSO. These spectra are typical of xanthene derivatives.

Table 1: Spectral and Fluorescence Data for Fluorescein in Various Solvents

\begin{tabular}{|c|c|c|c|c|c|}
\hline & $\mathrm{n}$ & $\lambda_{\mathrm{Q}}(\mathrm{Abs}) / \mathrm{nm}(\log \varepsilon)$ & $\lambda_{\mathrm{Q}}(\mathrm{Ems}) / \mathrm{nm}$ & $\mathrm{E}_{\mathrm{S}} / \mathrm{eV}$ & $\Phi_{\mathrm{F}}$ \\
\hline Methanol & 1.326 & $\begin{array}{l}478(72406) \\
452(77790)\end{array}$ & 520 & 2.39 & 0.90 \\
\hline PBS 7.4 & 1.332 & $488(77500)$ & 525 & 2.37 & 0.91 \\
\hline DMF & 1.430 & $\begin{array}{l}490(93000) \\
525(95700)\end{array}$ & 515 & 2.41 & 0.93 \\
\hline DMSO & 1.633 & $\begin{array}{l}487(73825) \\
453(70271)\end{array}$ & 545 & 2.28 & 0.95 \\
\hline
\end{tabular}




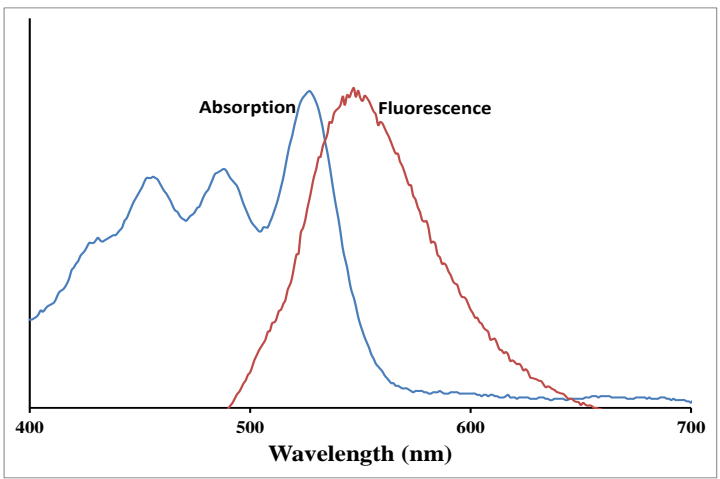

Fig. 3: Normalized Absorption and Fluorescence Spectra of Fluorescein in DMSO.

\subsection{Fluorescein fluorescence quenching by benzoquinone (BQ)}

The effect of benzoquinone (BQ) on the fluorescence of fluorescein in water in demonstrated in Fig. 4 (A similar trend was observed in other solvents used in this work). The tendency of BQ to quench the fluorescence of organic macrocycles is well documented in the literature (Ogunsipe \& Nyokong 2005b, Ogunsipe \& Nyokong 2011, Ogunsipe 2018, Gazdaru 2001). The sustained reduction in fluorescein's fluorescence intensity with increase in BQ concentration is an attestation to the fluorescence quenching ability of BQ on xanthene derivatives. A plot of Io/I versus [BQ] (Eq. 2) is linear (Fig. 4 inset), which implies an exclusively dynamic quenching. There was no alteration to the absorption spectra upon addition of $\mathrm{BQ}$; hence the existence of static quenching is ruled out.

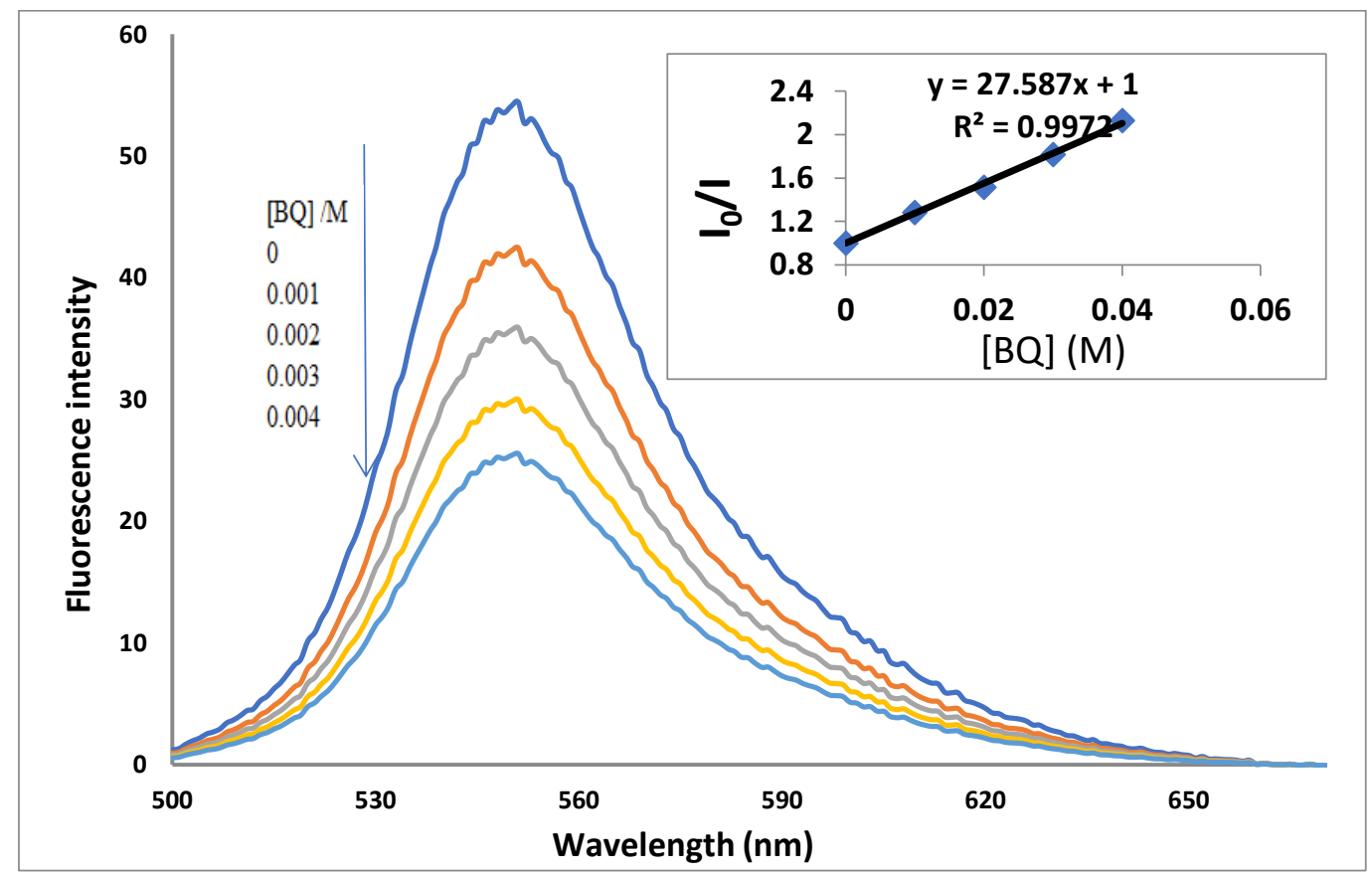

Fig. 4: Fluorescein Fluorescence Quenching by Benzoquinone in Water (Inset: Stern-Volmer Plot for the Quenching Process).

In effect, the operational quenching mechanism involves a diffusion-controlled collisional interaction between fluorescein and the BQ molecules; and under this situation, f, the quenching efficiency (Eq. 4) is assumed to be $\cong 1$. Diffusion coefficients of fluorescein (DFrr) and $\mathrm{BQ}\left(\mathrm{D}_{\mathrm{BQ}}\right)$ (Table 2), in the various solvents were calculated using Eq. 6; and these were in turn used to calculate the diffusioncontrolled bimolecular rate constant $\left(\mathrm{k}_{\mathrm{d}}\right)$ for the quenching of fluorescein by BQ. The Stern-Volmer quenching constant (Ksv, Table 2), determined as the slope of the plot in Fig. 4, ranged between $17.4 \mathrm{M}^{-1}$ (in DMSO) and $43.4 \mathrm{M}^{-1}$ (in methanol).

Table 2: Data for Fluorescein Fluorescence Quenching by Benzoquinone in Various Solvents

\begin{tabular}{|c|c|c|c|c|c|c|c|}
\hline & $\eta / 10^{-4} \mathrm{~kg} \mathrm{~m}^{-1}$ & $\mathrm{D}_{\text {Flrc }} / 10^{-10} \mathrm{~m}^{2} \mathrm{~s}^{-1}$ & $\mathrm{D}_{\mathrm{BQ}} / 10^{-10} \mathrm{~m}^{2} \mathrm{~s}^{-1}$ & ${ }^{\dagger} \mathrm{k}_{\mathrm{d}} / 10^{9} \mathrm{M}^{-1} \mathrm{~s}^{-1}$ & $\mathrm{~K}_{\mathrm{SV}} / \mathrm{M}^{-1}$ & $\tau_{\mathrm{F}} / \mathrm{ns}$ & $\Phi_{\mathrm{F}}$ \\
\hline Methanol & 5.43 & 9.23 & 10.3 & 12.2 & 43.4 & 3.55 & 0.90 \\
\hline PBS 7.4 & 8.90 & 5.63 & 6.28 & 7.45 & 27.6 & 3.71 & 0.91 \\
\hline Ethanol & 10.74 & 4.67 & 5.22 & 6.18 & 23.4 & 3.78 & 0.91 \\
\hline DMSO & 19.9 & 2.52 & 2.81 & 3.33 & 17.4 & 4.51 & 0.95 \\
\hline
\end{tabular}


It is assumed that $\mathrm{f}$ (quenching efficiency) unity; in which case $\mathrm{k}_{\mathrm{d}}=\mathrm{k}_{\mathrm{Q}}$ (Eq. 4).

There exists a correlation between the Stern-Volmer quenching constant $\left(\mathrm{K}_{\mathrm{SV}}\right)$ and solvent viscosity; the more viscous the solvent, the lower the $\mathrm{K}_{\mathrm{sv}}$ value. Fig. 5 demonstrates the dependence of $\mathrm{K}_{\text {sv values on solvent viscosity. }}$

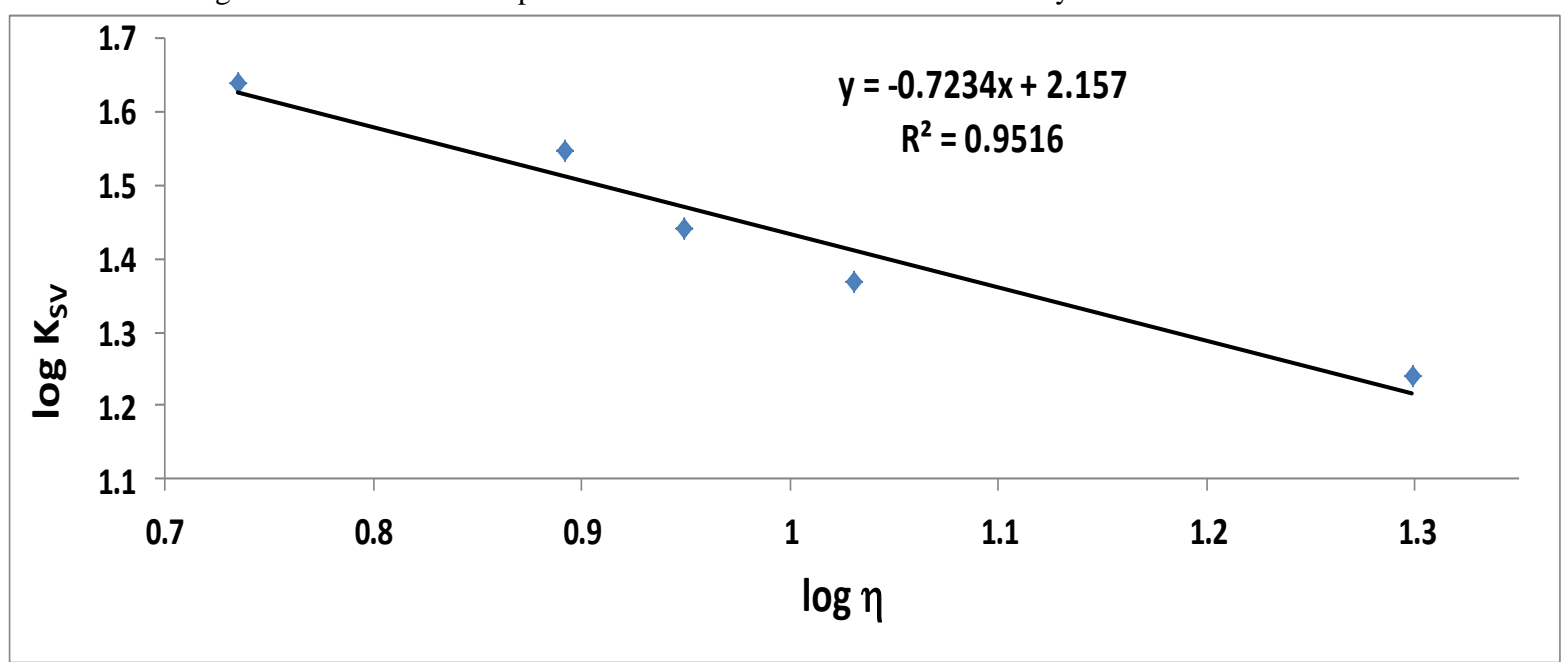

Fig. 5: Dependence of Stern-Volmer's Quenching Constant on Solvent Viscosity.

In DMSO, the motion of both the fluorophore (fluorescein) and quencher (BQ) are slowed down, thereby hindering the frequency of their collision. We propose a phenomenological relation for the variation of Ksv with solvent viscosity (Eq. 8a, b).

$\log K_{S V}=k+\log \eta$.

$\log K_{S V}=2.157-0.7234 \log \eta$.

The mechanism of fluorescence quenching could be via energy transfer (from the excited fluorescein to BQ) or charge transfer (between excited fluorescein and BQ). The highest energy excited singlet state energy of fluorescein in Table 1 is $2.41 \mathrm{eV}$, which is even lower than the lowest excited state ${ }^{1}\left(\mathrm{n}, \pi^{*}\right)$ energy in BQ (2.6 eV) (Losev et al. 1999). It follows that the Flrc* $\rightarrow$ BQ energy transfer is 'uphill' and therefore not practicable; and one can safely conclude that the quenching process is bimolecular photo-induced electron transfer (BPET) from the excited singlet state of fluorescein to BQ. An electronically excited fluorescein molecule has a great propensity to give away an electron nearby BQ molecules, and also to replace the removed electron to its original position in the molecule (Rabnowich 1945). As opined before, the quenching occurred via an ion-radical pair intermediate (Ogunsipe \& Nyokong 2011). The thrust behind the oxidizing ability of $\mathrm{BQ}$ is its high electron affinity (1.89 eV (Cooper et al. 1975)) in addition to the development of a resonancestabilized aromatic system of the semiquinone anion radical (Scheme 1).
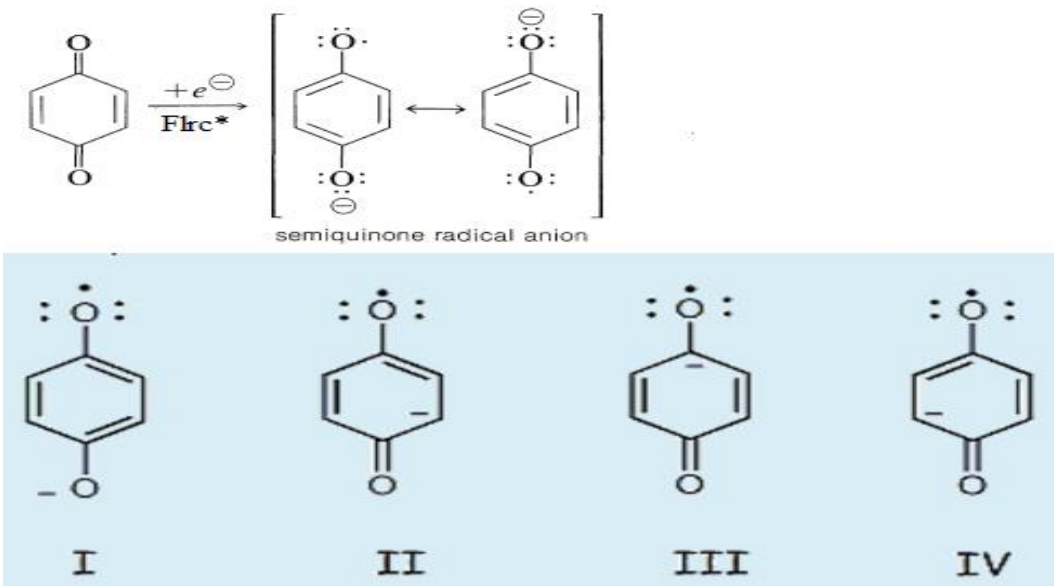

Scheme 1: Flrc ${ }^{*} \rightarrow$ BQ Electron Transfer and Resonance Structures of the Resulting Semiquinone Anion Radical.

The high electron affinity and stability of the resonance structures account for the formation of charge-transfer complexes between BQ and electron donors (Laird 1979).

The transferred electron can go back to fluorescein via a process known as back electron transfer (BET), which is an 'energy-wasting' process as it regenerates the fluorescein and BQ molecules in their ground states (Scheme 2).

Flrc $\stackrel{\mathrm{h} v}{\rightarrow}$ Flrc $^{*}$

$\mathrm{Flrc}^{*}+\mathrm{BQ} \stackrel{\mathrm{ET}}{\rightarrow} \mathrm{Flrc}^{+.} \ldots \ldots \mathrm{BQ}^{-}$(Charge separation)

Flrc $^{+.} \ldots \ldots \mathrm{BQ}^{-} \stackrel{\mathrm{BET}}{\longrightarrow}$ Flrc $+\mathrm{BQ}$ 
Scheme 2: Fluorescence quenching of fluorescein via charge transfer to benzoquinone $(\mathrm{ET}=$ electron transfer; $\mathrm{BET}=\mathrm{Back}$ electron transfer.

\subsection{Fluorescence lifetimes and quantum yields}

Values of Fluorescence lifetimes $\left(\tau_{\mathrm{F}}\right)$ and quantum yields $\left(\phi_{\mathrm{F}}\right)$ for fluorescein in the five solvents are listed in Table 2. $\tau_{\mathrm{F}}$ values were estimated according to using $\mathrm{K}_{\mathrm{SV}}$ and $\mathrm{k}_{\mathrm{Q}}$, Eq. 3. A trend of increasing $\tau_{\mathrm{F}}$ and $\phi_{\mathrm{F}}$ with increasing solvent viscosity is clear from the table (though not much pronounced in $\phi_{\mathrm{F}}$ values). A highly viscous solvent would impede translational and rotational motions in the fluorecein molecules, and may also inhibit the deformation of its structure through viscous damping by the solvent (Ogunsipe \& Nyokong 2011, Georghiou \& Stacy Gerke 1999). This ultimately results is a lowering of the excited singlet state decay rate constant (ks). In low-viscosity solvent however, free rotational diffusions about $\sigma$-bonds (the benzoic acid addendum about a C-C bond, hydroxyl group about a $\mathrm{C}-\mathrm{O}$ bond, and hydrogen atom about an $\mathrm{O}-\mathrm{H}$ bond) result in a new equilibrium state where the rate of internal conversion will undoubtedly be high and the excited molecule fast deactivated. The fluorescence lifetimes determined in this work might be expected to be shorter than those obtained by direct instrumentation. For example in this work, the fluorescence lifetime of fluorescein in PBS 7.4 is $3.71 \mathrm{~ns}$, which is shorter than a literature value of $4.0 \mathrm{~ns}$ (Magde et al. 1999). This discrepancy could be attributed to the crucial assumption made in this work, that the quenching efficiency in Eq. 4 is unity; in which case the bimolecular rate constant for diffusion-controlled reactions $\left(\mathrm{k}_{\mathrm{D}}\right)$ is assumed to be equal to the apparent bimolecular quenching constant $\left(\mathrm{k}_{\mathrm{Q}}\right)$. It is very unlikely that $\mathrm{k}_{\mathrm{D}}$ will be equal to $\mathrm{k}_{\mathrm{Q}}$ (it is expected that $\mathrm{k}_{\mathrm{Q}}$ should be less than $\mathrm{k}_{\mathrm{D}}$ (in which case $\mathrm{f}$ is less than 1 ).

\section{Conclusion}

The fluorescence lifetimes of fluorescein in different solvents have been estimated via a relatively unfamiliar procedure, which involves the application of fluorescence quenching data. Fluorescein's fluorescence was effectively quenched by benzoquinone within the latter's concentration range of $0.001-0.004 \mathrm{M}$. The quenching process is dynamic (diffusion-controlled collisional interaction between the fluorophore and quencher) as judged by the linearity of the Stern-Volmer's plot of the quenching data. Fluorescein's fluorescence quenching by 1,4-benzoquinone is believed to have been via charge transfer, and not energy transfer, since the latter is 'uphill' and therefore not plausible. Fluorescence lifetimes exhibit a well-pronounced dependence on solvent viscosity, with the longest lifetime being obtained in DMSO, the most viscous of the solvents used in this work. However, fluorescence quantum yield values only exhibit a slight dependence on solvent viscosity.

\section{Acknowledgement}

Thanks to Professor Tebello Nyokong of Rhodes University for the use of her laboratory.

\section{References}

[1] Al H, Henderson JN, Remington SJ \& Campbell RE (2006) Directed evolution of a monomeric, bright and photostable version of Clavularia cyan fluorescent protein: structural characterization and applications in fluorescence imaging. Biochemical Journal 400, 531-540. https://doi.org/10.1371/journal.pone.0017896.

[2] Al-Aqmar DM, Abdelkader HI \& Abou Kana MTH (2015) Spectroscopic properties and amplified spontaneous emission of fluorescein laser dye in ionic liquids as green media. Optical Materials 47, 573-581. https://doi.org/10.1016/j.optmat.2015.06.045.

[3] Becker W (2012) Fluorescence lifetime imaging-techniques and applications. Journal of Microscopy 247(2), 119-136. https://doi.org/10.1111/j.1365-2818.2012.03618.x.

[4] Burchak ON, Mugherli L, Chatelain F, Balakirev MY (2006) Fluorescein-Based Amino Acids for Solid Phase Synthesis of Fluorogenic Protease Substrates. Bioorganic and Medicinal Chemistry 14, 2559-2568. https://doi.org/10.1016/j.bmc.2005.11.037.

[5] Cooper CD, Naff WT \& Compton RN (1975) Negative ion properties of p-benzoquinone: Electron affinity and compound states. Journal of Chemical Physics 63(6), 2752-2757. https://doi.org/10.1063/1.431627.

[6] Fery-Forgues S \& Lavabre D (1999) Are Fluorescence Quantum Yields So Tricky to Measure? A demonstration using familiar stationery products. Journal of Chemical Education 76, 1260-1264. https://doi.org/10.1021/ed076p1260.

[7] Georghiou S \& Stacy Gerke L (1999) Excited-state properties of thymidine and their relevance to its heterogeneous emission in double-stranded DNA. Photochemistry Photobiology 69, 646-652. https://doi.org/10.1111/j.1751-1097.1999.tb03340.x.

[8] Govindanunny T \& Sivaram BM (1980) Solvation effects on the tunability of a fluorescein dye laser. Optics Communications 32, 425-428. https://doi.org/10.1016/0030-4018(80)90276-X.

[9] Ha SW, Camalier CE, Beck GR Jr \& Lee JK (2009) New method to prepare very stable and biocompatible fluorescent silica nanoparticles. Chemical Communications (Camb) 20, 2881-2883. https://doi.org/10.1039/b902195g.

[10] He L, Olson DP, Wu X, Karpova T, McNally JG \& Lipsky PE (2003) A flow cytometric method to detect protein-protein interaction in living cells by directly visualizing donor fluorophore quenching during CFP-YFP fluorescence resonance energy transfer (FRET). Cytometry Part A 55A, 7185. https://doi.org/10.1002/cyto.a.10073.

[11] Jose M, Nair DK, Reissner C, Hartig R \& Zuschratter W (2007) Photophysics of Clomeleon by FLIM: Discriminating Excited State Reactions Along Neuronal Development. Biophysical Journal 92, 2237-2254. https://doi.org/10.1529/biophysj.106.092841.

[12] Laird T (1979) Comprehensive Organic Chemistry, (Stoddart JF ed.), Pergamon press Ltd., Oxford, Vol. 1, p. 1214.

[13] Lakowicz JR (1999) Principles of Fluorescence Spectroscopy. Kluwer Academic/Plenum Publishers, New York. https://doi.org/10.1007/978-14757-3061-6.

[14] Losev AP, Volkovich DI \& Tikhomirov SA (1999) Intramolecular photoinduced electron transfer in Pd-porphyrin-quinone in the picosecond time. Journal of Applied Spectroscopy 66, 7-14. https://doi.org/10.1007/BF02679212.

[15] Ma LY, Wang HY \& Xie H (2004) A long lifetime chemical sensor: study on fluorescence property of fluorescein isothiocyanate and preparation of $\mathrm{pH}$ chemical sensor. Spectrochimica Acta A: Molecular and Biomolecular Spectroscopy. 60(8-9), 1865-72. https://doi.org/10.1016/j.saa.2003.10.004.

[16] Magde D, Rojas GE \& Seybold PG (1999) Solvent Dependence of the Fluorescence Lifetimes of Xanthene Dyes. Photochemistry Photobiology 70(5), 737-744. https://doi.org/10.1111/j.1751-1097.1999.tb08277.x.

[17] Maree S, Phillips D \& Nyokong T (2002) Synthesis, photophysical and photochemical studies of germanium and tin phthalocyanine complexes. Journal of Porphyrins and Phthalocyanines 6, 17-25. https://doi.org/10.1142/S108842460200004X 
[18] Montalban A, Meunier H, Ostler R, Barrett A, Hoffman B \& Rumbles, G (1999) Photoperoxidation of a diamino zinc porphyrazine to the seco-zinc porphyrazine: suicide or murder? Journal of Physical Chemistry A 103(22), 4352-4358. https://doi.org/10.1021/jp9905068.

[19] Ogunsipe A \& Nyokong T (2005a) Photophysical and photochemical studies of sulphonated non-transition metal phthalocyanines in aqueous and non-aqueous media. Journal of Photochemistry and Photobiology A: Chemistry 173, 211-220. https://doi.org/10.1016/j.jphotochem.2005.03.001.

[20] Ogunsipe A \& Nyokong T (2005b) Effects of central metal on the photophysical and photochemical properties of non-transition metal sulfophthalocyanine. Journal of Porphyrins and Phthalocyanines 9, 121-129. https://doi.org/10.1142/S1088424605000186.

[21] Ogunsipe A \& Nyokong T (2011) Solvent effects on the photophysicochemical properties of tetra(tert-butylphenoxy)phthalocyaninato zinc(II). Acta Physico-Chimica Sinica 27(5), 1045-1052.

[22] Ogunsipe A (2018) Solvent effects on the spectral properties of rhodamine 6G: estimation of ground and excited state dipole moments. Journal of Solution Chemistry 47, 203-219. https://doi.org/10.1007/s10953-017-0706-8.

[23] Oliveira E, Bértolo E, Núñez C, Pilla V, Santos HM, Fernández-Lodeiro J, Fernández-Lodeiro A, Djafari J, Capelo JL \& Lodeiro C (2018) Green and Red Fluorescent Dyes for Translational Applications in Imaging and Sensing Analytes: A Dual-Color Flag. ChemistryOpen 7, 9-52. https://doi.org/10.1002/open.201700135.

[24] Rabnowitch E (1945) Photosynthesis and Related Processes, Interscience, New York.

[25] Rajagopal S, Egorova EA, Bukhov NG \& Carpentier R (2003) Quenching of excited states of chlorophyll molecules in submembrane fractions of Photosystem I by exogenous quinones. Biochimica et Biophysica Acta 1606, 147-152. https://doi.org/10.1016/S0005-2728(03)00111-7.

[26] Veres P, Király G, Nagy G, Lázár I, Fábián I \& Kalmár J (2017) Biocompatible silica-gelatin hybrid aerogels covalently labeled with fluorescein. Journal of Non-Crystalline Solids 473, 17-25. https://doi.org/10.1016/j.jnoncrysol.2017.07.016.

[27] Xiong X, Song F, Wang J, Zhang Y, Xue Y, Sun L, Jiang N, Gao P, Tian L \& Peng X (2014) Thermally Activated Delayed Fluorescence of Fluorescein Derivative for Time-Resolved and Confocal Fluorescence Imaging. J. Am. Chem. Soc 136, 9590-9597. https://doi.org/10.1021/ja502292p.

[28] Zhang H, Zhang M \& Shen T (1997) Photoinduced intramolecular electron transfer of fluorescein and violgen, carbazole. Science in China Series B-Chemistry 40(5), 449-456. https://doi.org/10.1007/BF02875412.

[29] Zheng H, Zhan XQ, Bian QN \& Zhang XJ (2013) Advances in Modifying Fluorescein and Rhodamine Fluorophores as Fluorescent Chemosensors. Chemical Communications 49, 429-447. https://doi.org/10.1039/C2CC35997A. 